\title{
Stevens-Johnson Sendromu Sonrasında Gelişen Fox-Fordyce Hastalığı: Olgu Sunumu
}

\section{Fox-Fordyce Disease after Steven-Johnson Syndrome: Case Report}

Havva Yıldız Seçkin', Yalçın Baş', Akgül Arıcı' ${ }^{2}$ Zennure Takçı', Sercan Sezgin'1

${ }^{1}$ Gaziosmanpaşa Üniversitesi Tıp Fakültesi Deri ve Zührevi Hastalıkları Anabilimdalı, Tokat

${ }^{2}$ Gaziosmanpaşa Üniversitesi Tıp Fakültesi Patoloji Anabilimdalı, Tokat

\section{ÖZET}

Fox-Fordyce hastalığı (FFH), apokrin ter bezlerin kronik, nadir görülen, klinik olarak kaşıntılı papüllerle karakterize bir hastalığıdır. Kadınlarda daha sık görülür ve etyolojisi tam olarak net değildir. Bu makalede Stevens-Johnson Sendromu sonrasında dudaklarında FFD gelişen 19 yaşında bir erkek hasta sunuldu.

Anahtar kelimeler: Fox-Fordyce hastalığı, Stevens-Johnson Sendromu.

\section{ABSTRACT}

Fox-Fordyce Disease (FFD) is a rare, chronic disorder of the apocrin sweat glands and characterized by pruritic papules. The disease primarily affects females and the etiology is unclear. A 19-year-old male patient developed FFD in his lips with a history of Steven-Johnson Syndrome is presented in this report.

Key words: Fox-Fordyce disease, Steven-Johnson Syndrome.
Corresponding Author: Havva Yıldız Seçkin

Address: Gaziosmanpaşa Üniversitesi Tıp Fakültesi Deri ve Zührevi Hastalıkları Anabilimdalı, Tokat

E-mail: havvayildiz1982@mynet.com
Başvuru Tarihi/Received: 22-06-2015

Kabul Tarihi/Accepted: 21-07-2015 


\section{Giriş}

Fox-Fordyce hastalığı (FFH) apokrin ter bezlerinin etkilendiği nadir görülen, kaşıntılı, foliküler papüllerle karakterize kronik bir hastalığıdır. Klinik olarak özellikle aksilla olmak üzere areola, pubik bölge, umblikus, dudaklar ve perineum gibi apokrin bezlerin bulunduğu yerlerde deri renginde, kaşıntılı, birbirinden ayrık, folliküler papüller şeklinde görülür. Kadınlarda daha yaygındır ve genellikle 15-35 yaş arasında görülür (1-4). Etyopatogenezi tam olarak bilinmemektedir. Ancak apokrin ter bezi duktuslarının tıkanması ve rüptürünün önemli bir rol oynadığı düşünülmektedir (4). Ayrıca emosyonel, genetik, hormonal ve yapısal faktörlerle ilişkilendirilmiştir(5). Burada Stevens johnson syndrome(SJS) sonrasında dudaklarında FFD gelişen 19 yaşında bir erkek hasta sunuyoruz.

\section{OLGU SUNUMU}

17 yaşında erkek hasta bir yıldır dudaklarında küçük kabarıklıklar nedeniyle dermatoloji polikliniğine başvurdu. Öyküsünde on beş ay önce SJS tanısıyla hastanede yattığı öğrenildi. Üst solunum yolu infeksiyonu nedeniyle trimetoprim/ sulfametaksazol tedavisi alan ve tedavinin 10 . gününde her iki avuç içi ayak tabanı, dudaklar ve gözlerinde eritem, ödem ve vezikül/bül gelişmesi üzerine SJS tanısı konulan hasta yatarak tedavi edilmiş. Dudaklarında hemorajik karekterde krut gelişen hasta tedavi sonrasında tamamen düzelmesi üzerine taburcu edilerek takip önerilmiş. Taburcu edildikten 5 ay sonra her iki dudağının özellikle dış kısımlarında kabarıklıklar oluşmuş. Deri muayenesinde her iki dudağının dış kenarlarında üçgen şeklinde alanlar halinde, deri renginde, birbirinden ayrık, 1-2 mm çaplarında, çok sayıda papüler lezyonlar saptandı (Resim 1). Sistemik muayenesinde patolojik bir bulgu yoktu. Rutin laboratuar ve hormonal verileri normal sınırlar içindeydi. Aksiler, ingunial ve genital bölgelerin muayenesinde herhangi bir lezyon saptanmadı. Olgunun dudağından alınan punch biyopsi örneğinde, infundibular epitelde minimal spongioz, apokrin bezlerde dilatasyon ve dermiste inflamatuvar lenfohistiyositik infiltrasyon görüldü. Apokrin glandların, duktustaki obstruksiyon nedeniyle dilate görünümde olduğu gözlendi (Resim 2). Klinik ve histopatolojik bulgular sonucunda FFH tanısı konuldu.

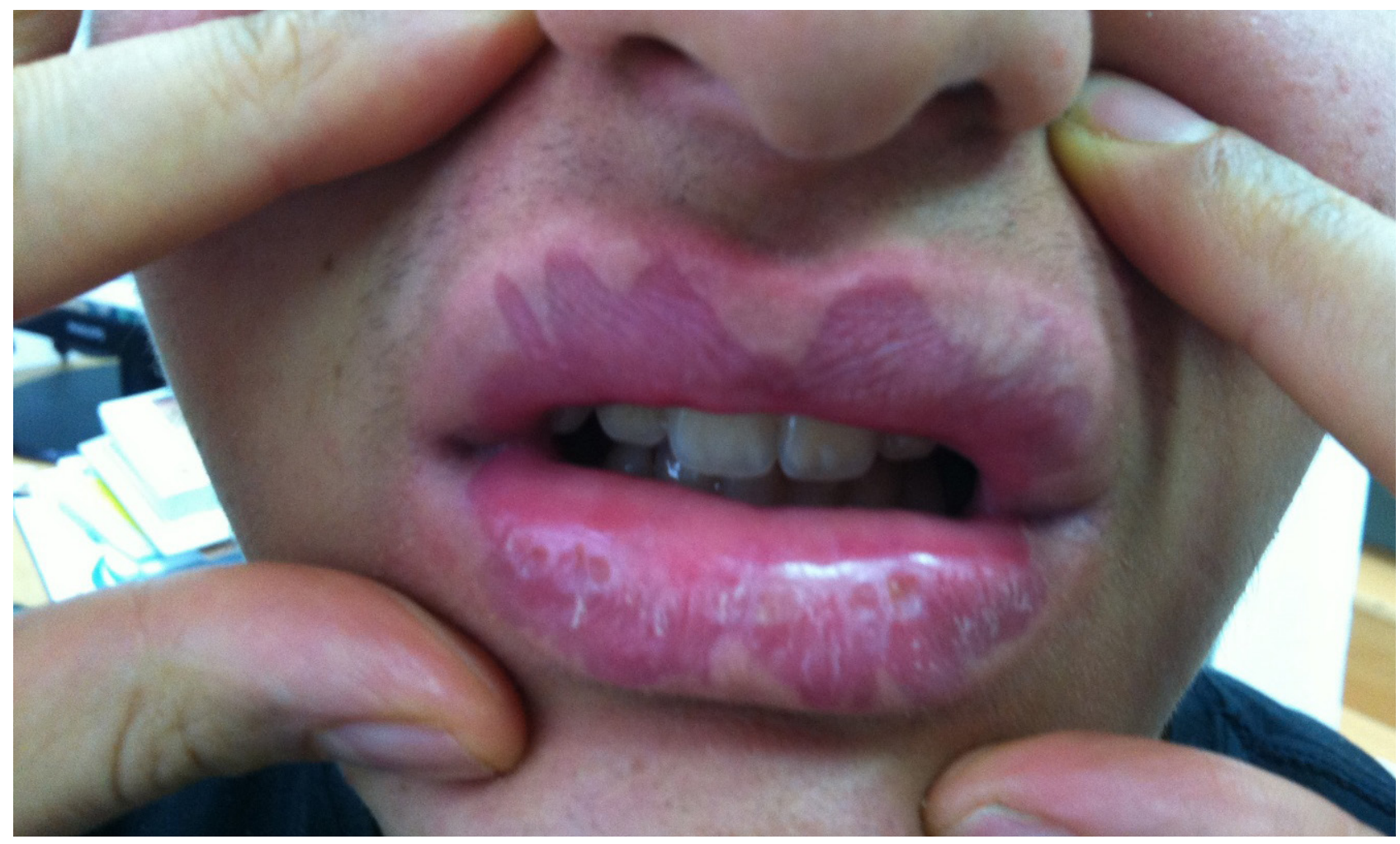

Resim 1: Her iki dudak kenarında deri renginde, birbirinden ayrık, 1-2 mm çaplarında, çok sayıda papüler lezyonlar. 


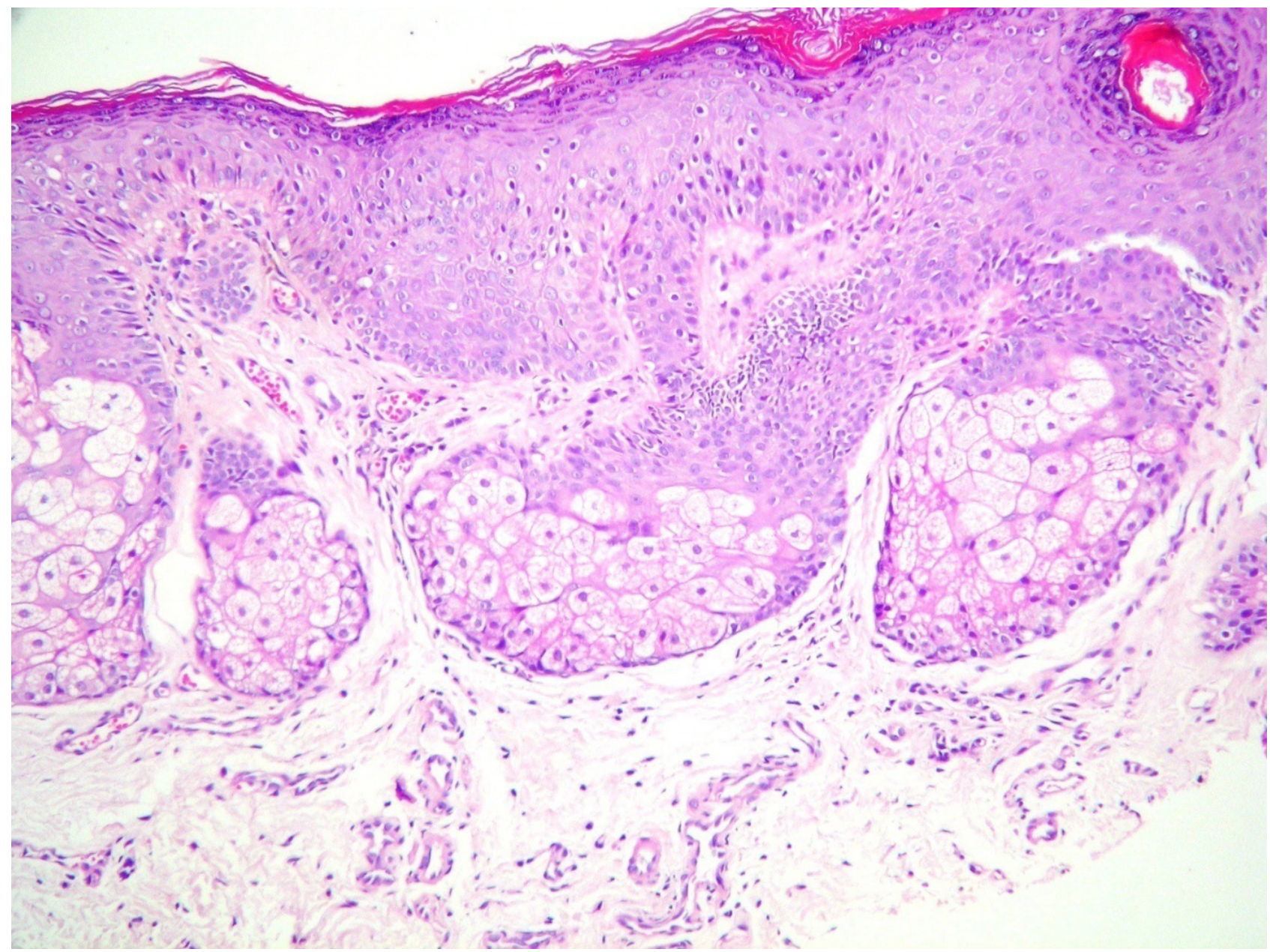

Resim 2: Subepitelyal alanda çok sayıda sebase bez yapıları (Hematoksilen - Eozin x 100)

\section{TARTIŞMA}

FFH nadir görülen, apokrin bezlerin bulunduğu bölgelere lokalize, kaşıntılı, kronik, papüler lezyonlarla karakterize sporadik bir hastalıktır. Olguların \%90'ı kadındır ve sıklıkla 15-35 yaş arasında görülür (6-7). Puberte öncesinde ve menopozdan sonra görülmesi nadirdir. HastaIığın etiyolojisi bilinmemesine rağmen genetik, emosyonel, hormonal ve yapısal faktörler üzerinde durulmaktadır. Östrojen verilmesinde ve hamileliğin başlangıçında semptomatik olarak iyileşmesi etiyolojide hormonal faktörlerin etkisini düşündürmektedir . Patogenezinde apokrin ter bezi duktuslarının tıkanması ve rüptürünün anahtar rol oynadığı bilinmektedir (1-5).

Histopatolojik olarak, folliküler ağızın ortokeratotik hücrelerle obstrüksiyonu ile karakterizedir. Kıl follikülünün üst $1 / 3$ 'ünde ve üst dermal damarların çevresinde lenfositten zengin bir inflamatuar infiltrat bulunur. İnfundulum epitelin- de apokrin kanalın geniş seviyesinde spongiyöz gözlenir (8). FFH tedavisi zordur ve genel olarak kabul edilen bir tedavi şekli yoktur. Genellikle tedavi sırasında geçici bir düzelme görülür ve tedavi kesildikten sonra tekrarlama eğilimindedir (1-5).

SJS genellikle ilaçlara karşı gelişen, deri ve mukozaların akut seyirli ve şiddetli bir grup döküntülü hastalığıdır. Klinik olarak hızla gelişen, tipik olmayan hedef benzeri lezyonlar, yaygın purpuralar, epidermal ayrışma ve en az 2 mukozal alanın tutulmasıyla karakterizedir. Epidermal ayrışma \%10'un altındadır (9-10). En önemli etyolojik faktör olan ilaçlar vakaların en az \%50'sinde saptanabilmektedir (11). Olguların yaklaşık \%5'inde ise herhangi bir faktör saptanamamaktadır. Ayrıca infeksiyonlar, aşılar, lenfoma ve lösemi veya graft versus host (GVH) hastalğı da etyolojide rol oynamaktadır. En sık sülfonamid grubu antibiyotikler (özellikle trimetoprim/sulfametaksazol) 
olmakla beraber antikonvülzan ilaçlar, beta laktam grubu antibiyotikler, allopurinol ve steroid olmayan antiinflamatuvar ilaçların neden olduğu bildirilmiştir. Olgumuz üst solunum yolu infeksiyonu nedeniyle trimetoprim/sulfametaksazol tedavisi almış ve tedavinin 10. gününde özellikle dudaklarda başlayan oral mukoza, göz mukozası ve takibinde avuç içi ve ayak tabanında vezikül/ bül gelişmesi üzerine SJS tanısıyla yatırılarak tedavi almıştır. SJS'da dudaklar karakteristik olarak aşırı miktarda ve hemorajik özellikte krutlarla kaplıdır (12).

En önemli komplikasyonu sepsis ve solunum yetmezliğidir. Ciltte depigmentasyon, gözde entropion, konjonktival ülserasyon, skar ve perforasyon görülebilmektedir. En çok bilinen oral mukoza komplikasyonları ise skarla beraber dil papillalarının kalıcı kaybı, ciddi dental büyüme anomalileri, tükrük üretiminde ve niteliğindeki değişikliklere bağı olarak zararlı bakterilerde, diş çürümelerinde ve oral kandida prevelansında artıştır (13-15). FDH'nın patogenezinde apokrin ter bezi duktuslarının tıkanması ve rüptürünün önemli rol oynadığı bilinmektedir. Olgumuzda SJS'nun bu durumu tetiklemiş olabileceğini ve FDH gelişimini kolaylaştırmış olabileceğini düşünmekteyiz.

Bildiğimiz kadarıyla literatürde daha önce SJS sonrasında FDH gelişimi bildirilmemiştir ve bu ilk olgudur. Sonuç olarak FDH nadir görülen ve etolojisi net olarak bilinmeyen bir hastalıktır. Etyolojisinin aydınlatılmasında daha çok çalışmaya ihtiyaç vardır.

\section{KAYNAKLAR}

1. Odom RB, James WD, Berger TG. Diseases of the Skin Appendages. In Andrews' diseases of the skin. 9. baskı. Philadelphia: Saunders Co, 2000: .975-6.

2. Ozcan A, Senol M, Aydin NE, Karaca S, Sener S. FoxFordyce disease. J Eur Acad Dermatol Venereol. 2003 Mar;17(2):244-5.

3. Kamada A, Saga K, Jimbow K. Apoeccrine sweat duct obstruction as a cause for Fox-Fordyce disease. J Am Acad Dermatol 2003; 48: 453-455.

4. Sandhu K, Gupta S, Kanwar AJ. Fox fordyce disease in a prepubertal girl. Pediatr Dermatol 2005;22:89-90.

5. Mayser P, Gründer K, Nilles M, Schill WB (1993) FoxFordyce disease (apocrine miliaria). Hautarzt 44:309311.

6. Shelley WB, Levy EJ. Apocrine sweat retention in man. II: Fox-Fordyce disease (apocrine miliaria). Arch Dermatol 1956; 74: 38.

7. Gündüz K, Kandiloğlu AR, Köşk EE, Türel A, Türkdoğan P. A male patient with Fox-Fordyce disease. Turk J Dermatopathol 1998; 7: 63-5.

8. Stashower ME, Kriuda SJ, Turiansky GW. Fox-Fordyce disease:Diagnosis with transverse histologic sections. J Am Acad Dermatol 2000; 42: 89-91.

9. Roujeau JC: The spectrum of Stevens-Johnson syn- drome and toxic epidermal necrolysis: a clinical classification. J Invest Dermatol 1994;102:28-30.

10. Assier H, Bastuji-Garin S, Revuz J, Roujeau JC: Erythema multiforme with mucous membrane involvement and Stevens-Johnson syndrome are clinically different disorders with distinct causes. Arch Dermatol 1995;131:539-43.

11. Roujeau JC, Stern RS: Severe adverse cutaneous reactions to drugs. N Engl J Med 1994;331:1272-85.

12. Leaute-Labreze C, Lamireau T, Chawki D, Maleville J, Taieb A: Diagnosis, classification, and management of erythema multiforme and Stevens-Johnson syndrome. Arch Dis Child 2000;83:347-52.

13. Ranalli DN, Elliott MA, Whaley TM, Campagna Jr ED. Stevens-Johnson syndrome: report of case with abnormal root development. ASDC J Dent Child 1984;51(4):298-301.

14. Gaultier F, Rochefort J, Landru MM, Allanore L, Naveau A, Roujeau JC, et al. Severe and unrecognized dental abnormalities after drug-induced epidermal necrolysis. Arch Dermatol 2009;145(11):1332-3.

15. Koseki M, Maki Y, Matsukubo T, Ohashi Y, Tsubota K. Salivary flow and its relationship to oral signs and symptoms in patients with dry eyes. Oral Dis 2004;10(2):75-80. 